\title{
Quantitative Analysis of Residual Hydrogen on Platinum Surface by Atom Probe
}

\author{
Sunwei Chen, ${ }^{\mathrm{a}, \dagger}$ Ryo Murakami, ${ }^{\mathrm{a}}$ Koya Araki, ${ }^{\mathrm{a}}$ Masanori Owari ${ }^{\mathrm{a}, \mathrm{b}}$ \\ a Institute of Industrial Science, The University of Tokyo, 4-6-1 Komaba, Meguro-ku, Tokyo 153-0041, Japan \\ ${ }^{\mathrm{b}}$ Environmental Science Center, The University of Tokyo, 7-3-1 Hongo, Bunkyo-ku, Tokyo 113-0333, Japan \\ †Corresponding author: sunwei23@iis.u-tokyo.ac.jp
}

Received: 6 February, 2020; Accepted: 29 March, 2020; Published: 9 April, 2020

The paper reports results of a systematic investigation of electric field effects on residual $\mathrm{H}$ signals in atom probe analysis. Three species, $\mathrm{H}^{+}, \mathrm{H}_{2}{ }^{+}$, and $\mathrm{H}_{3}{ }^{+}$, can be detected on a Pt surface without gas introduction into the ultra-high vacuum chamber. The $\mathrm{H}^{+}$ions are more likely to be detected at a higher electric field. On the other hand, the $\mathrm{H}_{2}{ }^{+}$and $\mathrm{H}_{3}{ }^{+}$ions appear at the lower electric field. A comparison of residual $\mathrm{H}$ and a $\mathrm{D}_{2}$ gas confirmed that residual $\mathrm{H}$ is in the $\mathrm{H}_{2}$ gas form. $\mathrm{H}_{2}$ can be dissociated to $\mathrm{H}$ on the Pt surface. Consequently, $\mathrm{H}, \mathrm{H}_{2}$, and $\mathrm{H}_{3}$ coexist on the Pt surface and desorb at an appropriate electric field.

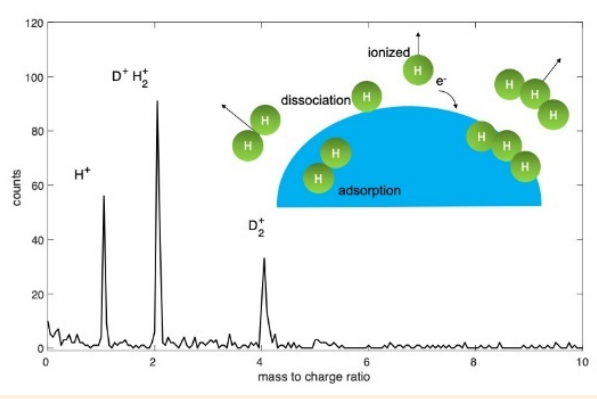

Keywords Residual hydrogen; Atom probe; Electric field; Adsorption; Dissociation

\section{INTRODUCTION}

Hydrogen $(\mathrm{H})$ embrittlement and corrosion are fundamental problems of material. Quantitative analysis of the hydrogen content in metal, however, remains great challenge due to tiny size, small mass to charge ratio and near-ubiquitous character of hydrogen element [1]. Several methods have been developed to study the relationship between hydrogen and metal. Thermal desorption spectroscopy can provide the adsorption and desorption information about hydrogen gas [2]. Secondary ion mass spectrometry can directly image hydrogen but cannot identify the precise location of the hydrogen atoms [3]. A transmission electron microscope (TEM) can only be used in specific case because of its projection and diffraction effects [4]. Atom probe (AP) is another potential candidate, which is capable of resolving individual atoms and identifying chemical position with a near-atomic resolution.

Several pioneer works have been made to detect $\mathrm{H}$ in AP analysis. Seidman found that $\mathrm{Nb}$ had a high solubility for hydrogen, which can be stored as deep as a whole detection range [5]. Advances have been made using ${ }_{1}^{2} \mathrm{H}$ (D) charging method as a substitute for ${ }_{1}^{1} \mathrm{H}$ in AP analysis $[1,6,7]$. However, residual $\mathrm{H}$ remaining in an AP ultra-high vacuum chamber limited the ability to quantify the $\mathrm{H}$ concentration in metals. The hydrogen gas $\left(\mathrm{H}_{2}\right)$ remaining in the ultra-high vacuum chamber could accumulate on the AP sample surface through a thermal accommodation process by virtue of a high electric field. In consequence, a significant amount of $\mathrm{H}_{2}^{+}$may cause an unwanted overlap with $\mathrm{D}^{+}$in the mass spectrum. Furthermore, the adsorbed residual gas also promotes the formation of metal hydride complex ions, further complicating hydrogen detection [8, 9]. Hence, improved insight and understanding into the effect of experimental parameters on the behavior of the residual $\mathrm{H}_{2}$ gas on a specimen tip surface is necessary for more accurate analysis of the $\mathrm{H}$ content in metals and alloys.

Several authors have investigated the relationship between residual $\mathrm{H}$ signals and experimental parameters in AP analysis. Prakash Kolli has systemically studied the laser pulse energy, the laser pulse frequency, and the tip base temperature effects on the residual hydrogen detection and suggested that the total quantity of the residual $\mathrm{H}_{2}$ gas can be changed in the mass spectra by varying the laser pulse energy and the pulse frequency [8]. Sundell et al. held the opinion that high direct current (DC) voltage could remove $\mathrm{H}_{2}{ }^{+}$from the spectrum [10]. It is considered that the electric field has a significant effect on the residual $\mathrm{H}$ signals in the aforementioned studies $[10,11]$. Nevertheless, no systematic investigation has been performed to define the relationship 
(a)
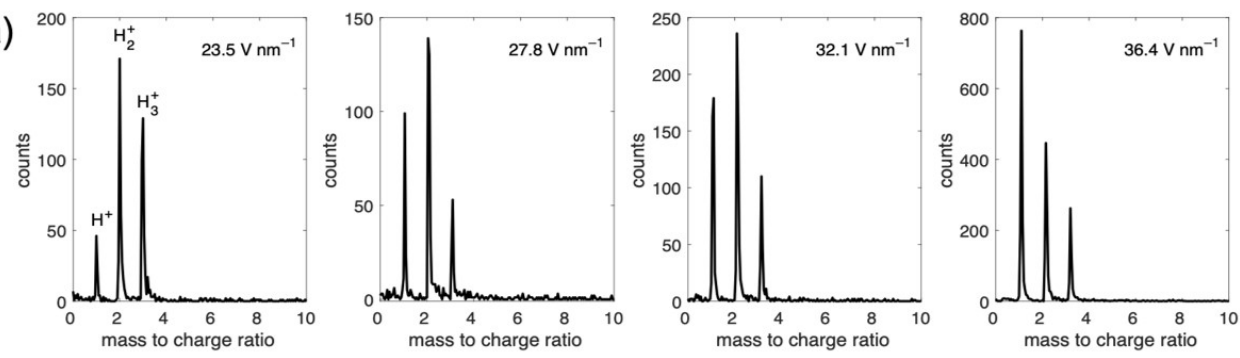

(b)
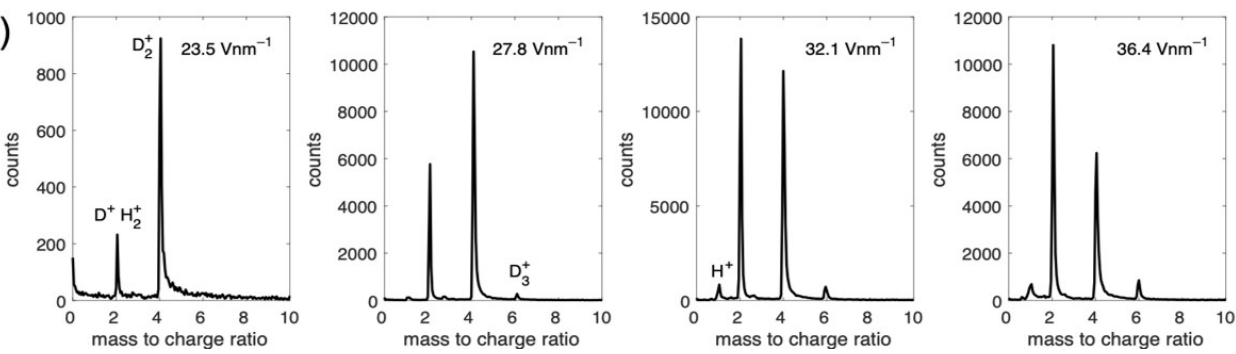

Figure 1: (a) Mass spectra of residual $\mathrm{H}$ on the Pt surface under the different electric field in the AP measurements $(60 \mathrm{~K})$. The background pressure was $10^{-8} \mathrm{~Pa}$. (b) Mass spectra of the $\mathrm{D}_{2}$ gas on the Pt surface under the different electric field $(60 \mathrm{~K})$. The pressure of the $\mathrm{D}_{2}$ gas was $2.0 \times 10^{-6} \mathrm{~Pa}$.

between electric field and the residual $\mathrm{H}$ signals. Additionally, the occurrence of the $\mathrm{H}_{3}{ }^{+}$signal remains still unsolved.

This study systematically studied electric field effects on the residual $\mathrm{H}$ signals by AP in a laser pulse mode. A platinum $(\mathrm{Pt})$ metal was utilized in this study because it has a high evaporation field and was reported to be hard to form hydrides in AP analysis. A comparison between the residual $\mathrm{H}$ signals and deuterium gas $\left(\mathrm{D}_{2}\right)$ signals was also performed to ascertain the source of residual $\mathrm{H}$. We also discussed the formation of all residual $\mathrm{H}$ signals.

\section{EXPERIMENT}

\section{A. Sample preparation}

A thin Pt wire (Nilaco, $\varnothing=0.1 \mathrm{~mm}, 99.99 \%$ ) was electropolished in a saturated $\mathrm{CaCl}_{2}$ solution to afford a $2-\mu \mathrm{m} \mathrm{Pt}$ tip. The etched Pt tip was then annularly milled by a focused ion beam scanning electron microscope (FIB-SEM, SII Nanotechnology, SMI-3050 SE) with a gallium liquid metal ion source (LMIS) to prepare a Pt tip with a diameter lower than $100 \mathrm{~nm}$. The diameter of the sample was measured by TEM (JEOL, JEM1010). The Pt surface was finally cleaned by cycles of field evaporation.

\section{B. Experiments}

All the experiments were performed by means of AP equipped with a femtosecond pulse laser $(532 \mathrm{~nm}, 300 \mathrm{fs}, 5$ $\mathrm{kHz}, 2.5 \mathrm{~nJ}$ pulse $^{-1}$ ), which was developed and constructed by our laboratory and has been described in detail elsewhere [12]. All the pressures mentioned here were measured by means of a Bayard-Alpert ion gauge. In the residual hydrogen experiment, no gas was introduced into the main cham- (a)

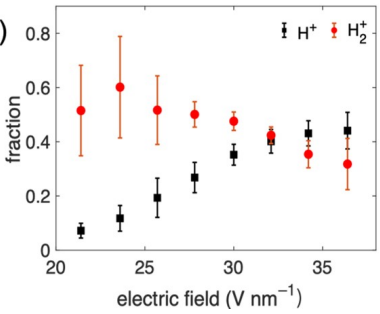

(b)

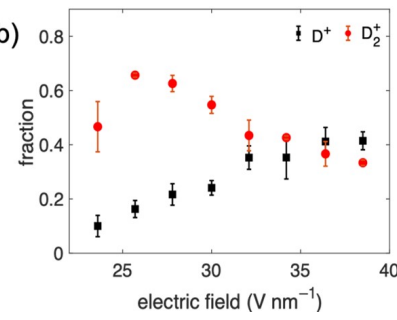

Figure 2: Plots of (a) hydrogen (Pt, $60 \mathrm{~K}$, background pressure: $10^{-8} \mathrm{~Pa}$ ) and (b) deuterium (Pt, $60 \mathrm{~K}, \mathrm{D}_{2}$ pressure: $\left.2.0 \times 10^{-6} \mathrm{~Pa}\right)$ signal fractions with respect to the electric field from $21.4 \mathrm{~V} \mathrm{~nm}^{-1}$ to $40 \mathrm{~V} \mathrm{~nm}^{-1}$. Black and red spots indicate the ratios of $\mathrm{H}^{+} / \mathrm{D}^{+}$and $\mathrm{H}_{2}{ }^{+} / \mathrm{D}_{2}{ }^{+}$against the total ion counts, respectively.

ber, and the background pressure was about $10^{-8} \mathrm{~Pa}$. In the $\mathrm{D}_{2}$ experiment, $\mathrm{D}_{2}$ was introduced into the main chamber, and the pressure of $\mathrm{D}_{2}$ was about $10^{-6} \mathrm{~Pa}$. The standing voltage required to ionize the $\mathrm{Pt}$ atoms at the sample apex was about $10.5 \mathrm{kV}$, corresponding to a static field of $E F_{\mathrm{dc}} \approx$ $45 \mathrm{~V} \mathrm{~nm}^{-1}$. The electric field $(E F)$ on the sample apex with different applied voltages can be calculated by the following equation [13];

$$
E F=V /(\beta R),
$$

where $V$ is a standing voltage, $R$ is a tip radius, and $\beta$ is a geometric factor. All the experiments were conducted with the electric field lower than the Pt evaporation field. All electric fields in this study refer to the static electric fields.

\section{RESULTS AND DISCUSSION}

\section{A. Residual hydrogen in AP analysis}

The residual hydrogen in the chamber in ultra-high vac- 

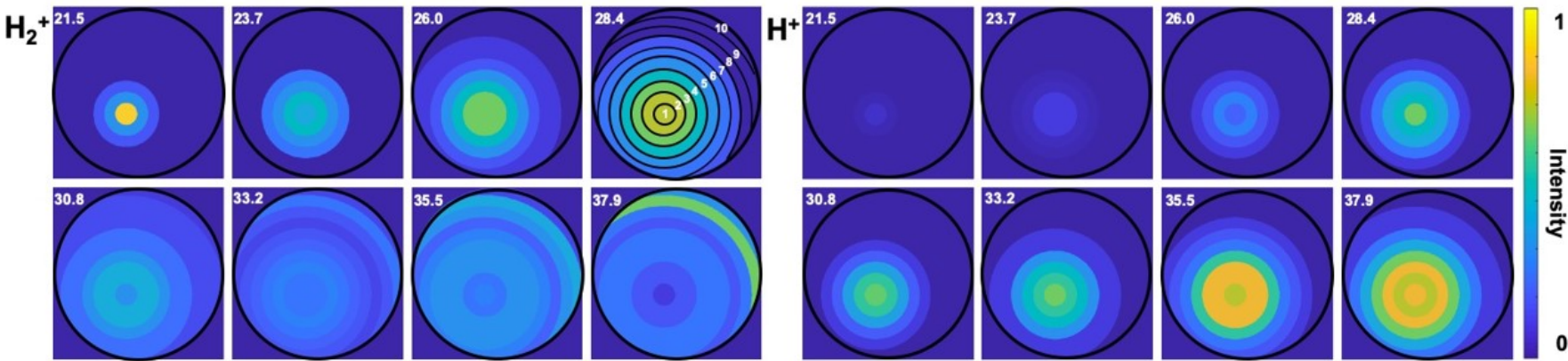

Figure 3: Contour maps of a normalized intensities of (a) $\mathrm{H}_{2}^{+}$and (b) $\mathrm{H}^{+}$on the Pt sample surface under various electric fields. The electric field values on the sample apex are shown in the upper left corner of each contour map with a unit of $\mathrm{V} \mathrm{nm}^{-1}$. The color bar indicates the normalized ion intensity.

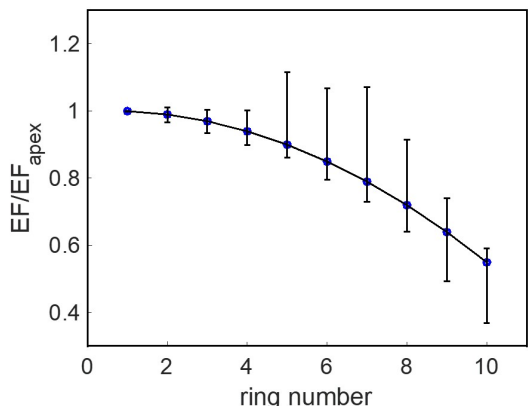

Figure 4: A plot of relative electric field $\left(E F / E F_{\text {apex }}\right)$ with respect to ring number.

uum condition $\left(10^{-8} \mathrm{~Pa}\right)$ and low temperature $(60 \mathrm{~K})$ was measured by AP. Figure 1(a) shows typical mass spectra of the $\mathrm{H}$ species on the Pt surface under various electric fields. In the MS spectra, three signals with the mass-to-charge state $(\mathrm{m} / \mathrm{n})$ ratio of 1,2 , and 3 Da were observed, which are assignable to $\mathrm{H}^{+}, \mathrm{H}_{2}^{+}$, and $\mathrm{H}_{3}^{+}$, respectively. Upon increasing electric field, the relative intensity of $\mathrm{H}^{+}$dramatically increased, while the relative ratio of $\mathrm{H}_{2}{ }^{+}$ions decrease, as shown in Figure 2(a). On the other hand, the ratio of $\mathrm{H}_{3}{ }^{+}$ was not strongly affected by electric field.

In order to evaluate the correlation of the signal intensity of $\mathrm{H}^{+}$and $\mathrm{H}_{2}{ }^{+}$with respect to electric field, the contour maps showing the normalized intensity of $\mathrm{H}^{+}$and $\mathrm{H}_{2}{ }^{+}$under various electric field were prepared (Figures 3 and 4). The contour maps of Figure 3 present the distribution of ions on a real sample under certain electric fields during AP analysis. In each contour map, the surface is divided into 10 rings, and the distribution of relative signal intensities of ions $\left(\mathrm{H}^{+}\right.$ and $\mathrm{H}_{2}^{+}$) from low to high are indicated by a color change from blue to yellow, respectively. The highest electric field stands on the first ring, suggesting the apex of the Pt sample. The electric field of the apex area was indicated on the upper left corner of each contour map. The relative values of the electric field $\left(E F / E F_{\text {apex }}\right)$ on these 10 concentric rings were calculated based on our previous work [14] (Figure 4).

Upon increasing the electric field from $21.5 \mathrm{~V} \mathrm{~nm}^{-1}$ to $28.4 \mathrm{~V} \mathrm{~nm}^{-1}$, the contour maps of $\mathrm{H}_{2}^{+}$showed a clear gradient that the $\mathrm{H}_{2}{ }^{+}$intensity increased from the outside to cen- tral rings. It is noted that substantial amount of $\mathrm{H}_{2}^{+}$was detectable even under a low electric field of $21.5 \mathrm{~V} \mathrm{~nm}^{-1}$. A continuous increase of the electric field, nevertheless, led to a decrease in the $\mathrm{H}_{2}{ }^{+}$intensity on the apex but an increase on the edge of the sample surface. In contrast, few $\mathrm{H}^{+}$was detected under $21.5 \mathrm{~V} \mathrm{~nm}^{-1}$. The intensity of $\mathrm{H}^{+}$exhibited a monotonic increase on the Pt surface and the highest intensity constantly resides on the apex, as the electric field increased from $21.5 \mathrm{~V} \mathrm{~nm}^{-1}$ to $37.9 \mathrm{~V} \mathrm{~nm}^{-1}$. These results indicate that a higher electric field is requisite to generate $\mathrm{H}^{+}$ than that for $\mathrm{H}_{2}^{+}$, which is in accordance with previous reports by Sundell et al. [10] and Kellogg [11].

\section{B. Source of residual hydrogen}

With regard to the source of residual hydrogen observed by AP analysis, we speculated that there are two candidates: (1) the adsorbed $\mathrm{H}_{2}$ molecules on the Pt surface; (2) the hydrogen atom/molecule embedded in the Pt metal. To seek the origin of residual hydrogen, we designed an AP measurement by introducing an additional $\mathrm{D}_{2}$ gas prior to $2.0 \times$ $10^{-8} \mathrm{~Pa}$ [Figure 1(b)]. The pressure increased to $2.0 \times 10^{-6}$ $\mathrm{Pa}$ after introducing the $\mathrm{D}_{2}$ gas. Upon applying the electric field on the Pt surface, several signals with the values of 1, 2, 4, and 6 Da were observed. While the signals of 1,4 , and 6 Da can be clearly assigned to $\mathrm{H}^{+}, \mathrm{D}_{2}{ }^{+}$, and $\mathrm{D}_{3}{ }^{+}$, respectively, the 2 Da signals would be the overlap of $\mathrm{H}_{2}{ }^{+}$and $\mathrm{D}^{+}$. Considering the fact that the $\mathrm{D}_{2}$ gas pressure was far larger than the base pressure $\left(2.0 \times 10^{-8} \mathrm{~Pa}\right)$, which is mainly caused by the residual $\mathrm{H}_{2}$ gas, the majority component of the $2 \mathrm{Da}$ signals is composed of the $\mathrm{D}^{+}$ions. Additionally, it has been found that the intensity of $\mathrm{H}_{2}^{+}$is comparable to that of $\mathrm{H}^{+}$ after applying an electric field as confirmed by Figure 1(a), so the significantly small peak derived from $\mathrm{H}+$ infers a negligible small amount of $\mathrm{H}_{2}{ }^{+}$, which would contribute to the $2 \mathrm{Da}$ signal. Therefore, the signals of 2 and $4 \mathrm{Da}$ can be used to discuss the variation of the $\mathrm{D}^{+}$and $\mathrm{D}_{2}{ }^{+}$ions as a function of the electric field. As shown in Figure 2(b), with an increase of the electric field, the signal intensity of $\mathrm{D}^{+}$ increases while that of $\mathrm{D}_{2}^{+}$decreases, which is consistent with the $\mathrm{H}^{+}$and $\mathrm{H}_{2}^{+}$fraction alterations measured under base pressure $\left(2.0 \times 10^{-8} \mathrm{~Pa}\right)$. 

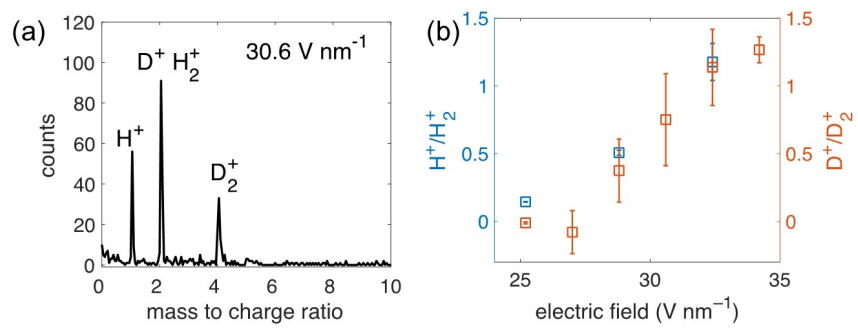

Figure 5: (a) Mass spectrum of residual hydrogen and deuterium on the Pt surface by the pulse laser with an electric field of $30.6 \mathrm{~V}$ $\mathrm{nm}^{-1}\left(6.0 \times 10^{-8} \mathrm{~Pa}, 60 \mathrm{~K}\right)$. The $\mathrm{D}_{2}$ gas pressure was reduced from $2.0 \times 10^{-6} \mathrm{~Pa}$ to $6.0 \times 10^{-8} \mathrm{~Pa}$. (b) A plot of the variation of the intensity ratios of $\mathrm{H}^{+} / \mathrm{H}_{2}{ }^{+}$and $\mathrm{D}^{+} / \mathrm{D}_{2}{ }^{+}$against the electric field.

Next, the $\mathrm{D}_{2}$ pressure was reduced to $6.0 \times 10-8 \mathrm{~Pa}$, where three signals of 1,2 , and 4 Da with comparable intensity were observed in the mass spectrum, suggesting the coexistence of hydrogen and deuterium on the Pt surface [Figure 5(a)] so that the $2 \mathrm{Da}$ signal is composed of both $\mathrm{H}_{2}{ }^{+}$ and $\mathrm{D}^{+}$ions. To clarify the ratio of these two ions, the intensities of the $\mathrm{H}_{2}{ }^{+}$and $\mathrm{D}^{+}$ions could be calculated as follows;

$$
\begin{aligned}
& I_{\mathrm{H}_{2}^{+}}=I_{\mathrm{H}^{+}} \times\left(\mathrm{H}_{2}^{+} / \mathrm{H}^{+}\right), \\
& I_{\mathrm{D}^{+}}=I_{2 \mathrm{D}}-I_{\mathrm{H}_{2}^{+}},
\end{aligned}
$$

where $I_{\mathrm{H}^{+}}$is the intensity of $\mathrm{H}_{2}{ }^{+}$ions, $I_{\mathrm{H}^{+}}$is the intensity of $\mathrm{H}^{+}, \mathrm{H}_{2}^{+} / \mathrm{H}^{+}$is the ratio of the $\mathrm{H}_{2}^{+}$intensity and the $\mathrm{H}^{+}$ intensity, $I_{D^{+}}$is the intensity of the $\mathrm{D}^{+}$ions, $I_{2 \mathrm{D}}$ is the peak intensity at a $m / n$ ratio of $2 \mathrm{Da}$. The proportions of $\mathrm{H}^{+} / \mathrm{H}_{2}{ }^{+}$and $\mathrm{D}^{+} / \mathrm{D}_{2}{ }^{+}$against electric field was shown in Figure 5(b) that almost superimposable variation trends were obtained. Taking account of all the results thus obtained, we concluded that the residual $\mathrm{H}$ detected in AP measurement originates from the $\mathrm{H}_{2}$ gas adsorbed on Pt surface rather than the hydrogen in the Pt tip. Figure 6 shows the surface distribution of $\mathrm{D}^{+}$and $\mathrm{D}_{2}{ }^{+}$on the Pt sample in the $\mathrm{D}_{2}$ gas atmosphere $\left(2.0 \times 10^{-6} \mathrm{~Pa}\right)$ by a pulse laser with an electric field of $27.8 \mathrm{~V} \mathrm{~nm}^{-1}$. The distribution of the $\mathrm{D}_{2}{ }^{+}$ions (green spots) on the Pt surface illustrated the areas with the higher local electric fields on the Pt surface. The $\mathrm{D}^{+}$ion distribution

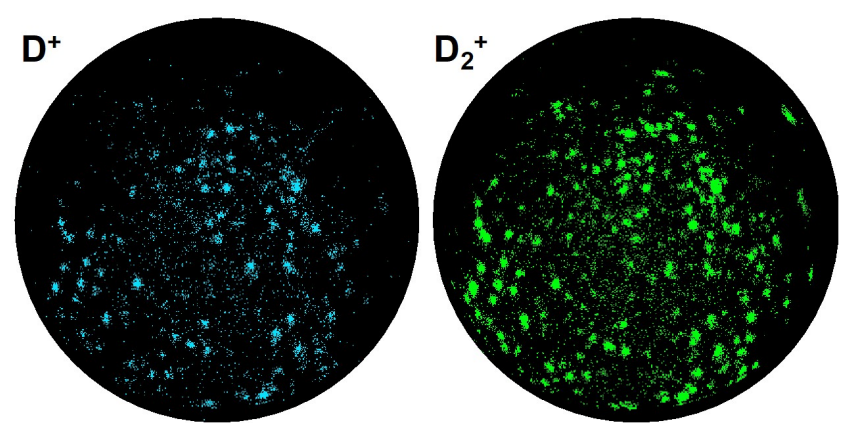

Figure 6: Two-dimensional distribution maps of the $\mathrm{D}^{+}$ions (left) and the $\mathrm{D}_{2}{ }^{+}$ions (right) on the Pt surface by the pulse laser with the electric field of $27.8 \mathrm{~V} \mathrm{~nm}^{-1}$ with the $\mathrm{D}_{2}$ gas atmosphere $(2.0 \times$ $10^{-6} \mathrm{~Pa}$ ) at $60 \mathrm{~K}$. The $\mathrm{D}_{3}{ }^{+}$ions were not detected in this condition.

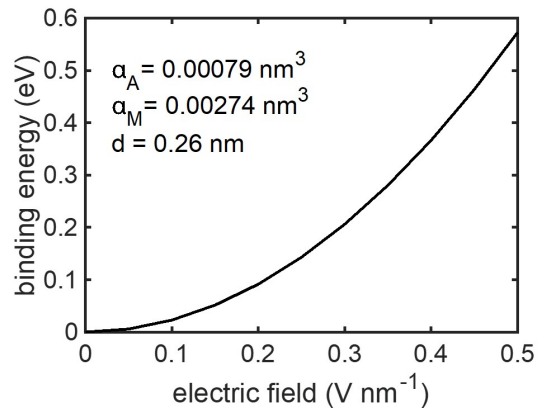

Figure 7: A plot of the binding energy for the field-adsorbed residual $\mathrm{H}_{2}$ gas on Pt metal surface atom as a function of the electric field.

(blue spots) showed a similar pattern, but the ion intensity was weaker, which also implied that the $\mathrm{D}_{2}{ }^{+}$ions were easier to be evaporated than the $\mathrm{D}^{+}$ions.

\section{Field Adsorption}

It was surprising to us that the maximum evaporation rate of the $\mathrm{H}$ species is as high as 17 counts/second even in ultra-high vacuum $\left(10^{-8} \mathrm{~Pa}\right)$. The accumulation and adsorption of the $\mathrm{H}_{2}$ gas on the AP sample surface can be ascribed to dipole-dipole interaction when subjected to a high electric field $[8,11,13]$. This model well describes the mechanism of gas adsorption in a short range. Here, the short-range is defined as an atomic radius or less. The binding energy $H_{\mathrm{A}}$ is expressed by the following equation;

$$
H_{\mathrm{A}}=\frac{1}{2} \alpha_{\mathrm{A}}\left(f_{\mathrm{A}}-1\right) F_{0}^{2},
$$

where $\alpha_{\mathrm{A}}$ is the polarizability of a gas atom or molecule, $F_{0}$ is the electric field, $f_{\mathrm{A}}$ is the enhancement factor given by

$$
f_{\mathrm{A}}=\left[\frac{1+\frac{\alpha_{\mathrm{M}}}{d^{3}}}{1-\frac{4 \alpha_{\mathrm{A}} \alpha_{\mathrm{M}}}{d^{6}}}\right]^{2},
$$

where $\alpha_{\mathrm{M}}$ is the polarizability of the substrate surface atom and $d$ is the equilibrium distance between the surface atom and the adsorbing species. Figure 7 exhibits the short-range binding energy of a $\mathrm{H}_{2}$ gas molecule on the Pt metal surface as a function of the electric field calculated using Eqs. (1) and (2). The binding energy increases monotonically with the electric field, suggesting that the $\mathrm{H}_{2}$ gas molecule would diffuse along the shank to sample apex due to the electric field gradient, which considerably improve the $\mathrm{H}_{2}$ gas concentration on the top of the sample surface even in the extremely high vacuum $[15,16]$.

\section{Field Desorption}

Having demonstrated the hydrogen adsorption on the Pt sample under the ultra-high vacuum for the AP measurement, we sought for the mechanism of the formation and desorp- 


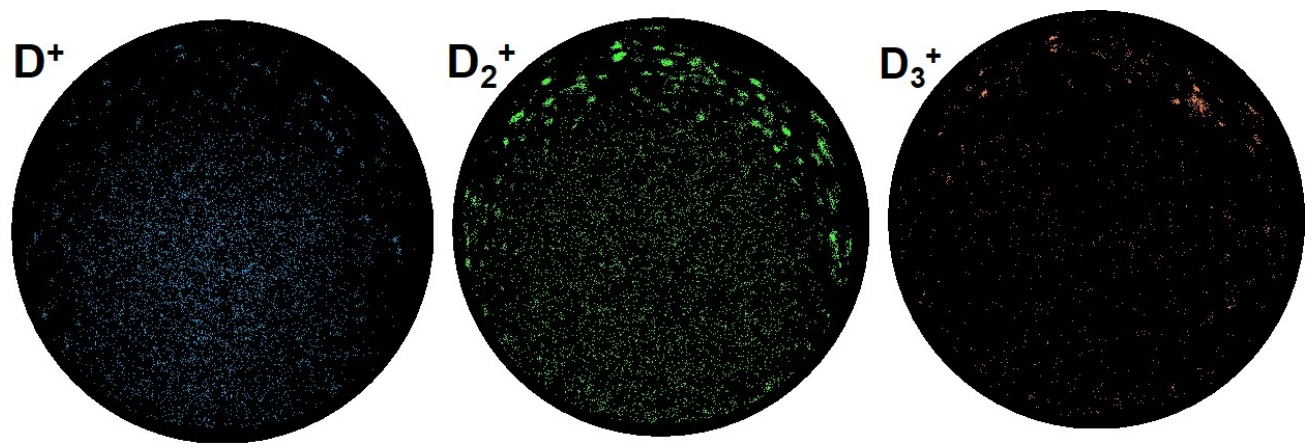

Figure 8: Two-dimensional distribution maps of the $\mathrm{D}^{+}$(left), $\mathrm{D}_{2}{ }^{+}$(middle), and $\mathrm{D}_{3}{ }^{+}$(right) ions on the Pt surface by the pulse laser with the electric field of $32.1 \mathrm{~V} \mathrm{~nm}^{-1}$ in the $\mathrm{D}_{2}$ gas atmosphere $\left(2.0 \times 10^{-6} \mathrm{~Pa}\right)$ at $60 \mathrm{~K}$.

tion of $\mathrm{H}^{+}, \mathrm{H}_{2}{ }^{+}$, and $\mathrm{H}_{3}{ }^{+}$on the Pt sample surface. In the Kellogg's model [11], an instantaneous temperature rise produced by the laser pulse thermally desorbs a molecule as a neutral species. This molecule is then ionized at the critical distance away from the surface with a sufficient electric field. This study also suggested the formation of the $\mathrm{H}_{2}{ }^{+}$ $\left(\mathrm{D}_{2}{ }^{+}\right)$ions is attributed to the $\mathrm{H}_{2}\left(\mathrm{D}_{2}\right)$ gas desorption triggered by a thermally activated process.

For the formation of the $\mathrm{H}_{3}^{+}\left(\mathrm{D}_{3}^{+}\right)$ion, three processes have been proposed: $\mathrm{H}_{2}^{+}+\mathrm{H} \rightarrow \mathrm{H}_{3}^{+}, \mathrm{H}_{2}+\mathrm{H}^{+} \rightarrow \mathrm{H}_{3}^{+}$, and $\mathrm{H}_{3} \rightarrow \mathrm{H}_{3}^{+}[9,13,14]$. The first two processes argued that an ion $\left(\mathrm{H}_{2}^{+}\right.$or $\left.\mathrm{H}^{+}\right)$collides a neutral atom or molecule to produce a $\mathrm{H}_{3}{ }^{+}$ion. However, once the atom or molecule was ionized, it would fly away from the sample surface so as to significantly reduce the collision possibility. Therefore, the formation $\mathrm{H}_{3}{ }^{+}\left(\mathrm{D}_{3}{ }^{+}\right)$can be rationalized by the direct desorption of the $\mathrm{H}_{3}\left(\mathrm{D}_{3}\right)$ molecule on the Pt surface. Although the $\mathrm{H}_{3}\left(\mathrm{D}_{3}\right)$ molecules are unstable in the free space, they could be stabilized in the presence of a high electric field. The formation of the $\mathrm{H}_{3}\left(\mathrm{D}_{3}\right)$ molecule stems from the combination of $\mathrm{H}_{2}\left(\mathrm{D}_{2}\right)$ and $\mathrm{H}(\mathrm{D})$, implying the coexistence of the molecules $\left[\mathrm{H}_{2}\left(\mathrm{D}_{2}\right)\right]$ and the atoms $[\mathrm{H}(\mathrm{D})]$ on the sample surface. We, thus, propose that the formation of triatomic cation can be expressed by the following equation [9];

$$
\mathrm{H}_{2}+\mathrm{H} \rightarrow \mathrm{H}_{3} \rightarrow \mathrm{H}_{3}^{+} \text {. }
$$

Figure 8 shows the surface distribution of $\mathrm{D}^{+}, \mathrm{D}_{2}^{+}$, and $\mathrm{D}_{3}^{+}$ on the Pt sample in the $\mathrm{D}_{2}$ gas atmosphere $\left(2.0 \times 10^{-6} \mathrm{~Pa}\right)$ by a pulse laser with an electric field of $32.1 \mathrm{~V} \mathrm{~nm}^{-1}$. The $2 \mathrm{D}$ distribution maps show that the predominance of the $\mathrm{D}_{2}^{+}$ and $\mathrm{D}_{3}{ }^{+}$ions appears at the edge of the sample surface, while the $\mathrm{D}^{+}$ions appear on the apex area, where the electric field was higher than the other area, indicating the electric field necessary to ionize $\mathrm{H}_{3}\left(\mathrm{D}_{3}\right)$ and $\mathrm{H}_{2}\left(\mathrm{D}_{2}\right)$ is lower than that for the $\mathrm{H}(\mathrm{D})$ atom.

In light of the conclusion drawn above, we interpret the formation of $\mathrm{H}^{+}\left(\mathrm{D}^{+}\right)$as follows. In the $\mathrm{H}_{3}\left(\mathrm{D}_{3}\right)$ formation process, $\mathrm{H}(\mathrm{D})$ atom is expected to originally exist on the $\mathrm{Pt}$ surface. The $\mathrm{H}^{+}\left(\mathrm{D}^{+}\right)$ions may desorbed from the strongly adsorbed $\mathrm{H}(\mathrm{D})$ atoms, which are generated from a dissociation of $\mathrm{H}_{2}\left(\mathrm{D}_{2}\right)$ on the Pt surface. As the binding energy of the $\mathrm{H}(\mathrm{D})$ atoms were much larger than that of the $\mathrm{H}_{2}\left(\mathrm{D}_{2}\right)$ molecules, the $\mathrm{H}^{+}\left(\mathrm{D}^{+}\right)$ions were emitted by high electric fields, while the $\mathrm{H}_{2}^{+}\left(\mathrm{D}_{2}^{+}\right)$ions require a low electric field. Our scenario is different from the Kellogg's one. In the Kellogg's model, it is suggested the occurrence of the $\mathrm{H}^{+}$ions is due to the desorption of $\mathrm{H}_{2}{ }^{+}$ions followed by ionization or dissociation of a subset of these ions, where high electric field permits this process [11]:

$$
\mathrm{H}_{2} \rightarrow \mathrm{H}_{2}^{+} \rightarrow \mathrm{H} / \mathrm{H}^{+}+\mathrm{H}^{+} \text {. }
$$

\section{CONCLUSIONS}

In summary, the residual hydrogen in the ultra-high vacuum on the Pt surface was systematically investigated by AP analyses. When the pressure is reduced to $10^{-8} \mathrm{~Pa}$, three hydrogen species can be detected on the Pt surface, including $\mathrm{H}^{+}, \mathrm{H}_{2}{ }^{+}$, and $\mathrm{H}_{3}{ }^{+}$. The $\mathrm{H}^{+}$ions are more likely to be detected at the high electric field; the observation of $\mathrm{H}_{2}{ }^{+}$and $\mathrm{H}_{3}{ }^{+}$requires a relatively low electric field. Labeling experiments using $\mathrm{D}_{2}$ revealed that residual $\mathrm{H}$ was from the $\mathrm{H}_{2}$ gas in the chamber. Calculations of the field-induced binding energy of the $\mathrm{H}_{2}$ gas and the sample surface reveal a considerable improvement of the $\mathrm{H}_{2}$ gas concentration on the sample surface upon apply a high electric field. It was found that $\mathrm{H}$ atoms, $\mathrm{H}_{2}$, and $\mathrm{H}_{3}$ molecules may coexist on the sample surface. This study further suggests when studying the $\mathrm{H}$ or $\mathrm{D}$ trapping in an AP sample, the background intensity of the $\mathrm{H}^{+}, \mathrm{H}_{2}{ }^{+}$, and $\mathrm{H}_{3}{ }^{+}$ions in certain operation parameters needs to be carefully analyzed, as these signals may overlap with the probed ion signal in mass spectra.

\section{Acknowledgments}

This work was supported by JSPS KAKENHI Grant Number $16 \mathrm{H} 03814$.

\section{References}

[1] Y. S. Chen, D. Haley, S. S. A. Gerstl, A. J. London, F. Sweeney, R. A. Wepf, W. M. Rainforth, P. A. J. Bagot, and M. P. Moody, Science 355, 1196 (2017).

[2] R. Lewis and R. Gomer, Surf. Sci. 17, 333 (1969).

[3] P. Kesten, A. Pundt, G. Schmitz, M. Weisheit, H. U. Krebs, and R. Kirchheim, J. Alloys Compd. 330-332, 225 (2002). 
[4] K. Tatsumi, S. Muto, and T. Yoshida, J. Appl. Phys. 101, 023523 (2007).

[5] Y.-J. Kim, R. Tao, R. F. Klie, and D. N. Seidman, ACS Nano 7, $732(2013)$.

[6] H. Takamizawa, K. Hoshi, Y. Shimizu, F. Yano, K. Inoue, S. Nagata, T. Shikama, and Y. Nagai, Appl. Phys. Express 6, 066602 (2013).

[7] J. Takahashi, K. Kawakami, Y. Kobayashi, and T. Tarui, Scr. Mater. 63, 261 (2010).

[8] R. Prakash Kolli, Adv. Struct. Chem. Imaging 3, 10 (2017).

[9] Z. M. Stepień and T. T. Tsong, Surf. Sci. 409, 57 (1998).

[10] G. Sundell, M. Thuvander, and H.-O. Andrén, Ultramicroscopy $\mathbf{1 3 2}, 285$ (2013).

[11] G. J. Kellogg, J. Chem. Phys. 74, 1479 (1981).

[12] N. Mayama, T. Iwata, C. Yamashita, S. Ito, T. Kaneko, S. Mikami, Y. Hanaoka, Y. Kajiwara, T. Kaito, T. Adachi, H. Hoshino, K. Nikawa, M. Nojima, M. Taniguchi, and M. Owari, Surf. Interface Anal. 42, 1616 (2010).

[13] T. T. Tsong and E. W. Müller, J. Chem. Phys. 55, 2884 (1971). [14] S. Chen, T. Suzuki, B. Tomiyasu, and M. Owari, Surf. Interface Anal. (2020) in press.
[15] M. J. Southon, Image Formation in the Field Ion Microscope, Ph.D. Thesis, University of Cambridge, 1963.

[16] H. D. Beckey, Principles of Field Ionization and Field Desorption Mass Spectrometry (Pergamon Press, Oxford, 1977) Chap. 1.

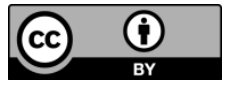

All articles published on e-J. Surf. Sci. Nanotechnol. are licensed under the Creative Commons Attribution 4.0 International (CC BY 4.0). You are free to copy and redistribute articles in any medium or format and also free to remix, transform, and build upon articles for any purpose (including a commercial use) as long as you give appropriate credit to the original source and provide a link to the Creative Commons (CC) license. If you modify the material, you must indicate changes in a proper way.

Published by The Japan Society of Vacuum and Surface Science 